\title{
Changes in occupational asthma during four decades in Slovakia, Central Europe
}

\author{
Slavomír Perečinský1,A,C-D,F, Lenka Murínová1,B,E-F, Peter Kalanin ${ }^{2, E}$, Andrea Jančová',B, \\ Lubomír Legáth ${ }^{1, A, E-F}$ \\ ' Department of Occupational Medicine and Clinical Toxicology, Medical Faculty, P. J. Safarik University / L. Pasteur \\ University Hospital, Kosice, Slovak Republic \\ ${ }^{2}$ Department of General Medicine, Medical Faculty, P. J. Safarik University and Kalanin s.r.o, Kosice, Slovakia \\ A - Research concept and design, B - Collection and/or assembly of data, C - Data analysis and interpretation, D - \\ Writing the article, $E$ - Critical revision of the article, $F$ - Final approval of article
}

Perečinský S, Murínová L, Kalanin P, Jančová A, Legáth L. Changes in occupational asthma during four decades in Slovakia, Central Europe. Ann Agric Environ Med. 2018; 25(3): 437-442. doi: 10.26444/aaem/89647

\begin{abstract}
Introduction. Occupational asthma $(\mathrm{OA})$ is the most common occupational lung disease in industrialized countries; however, in Western Europe, a decline in the prevalence of OA and changes in etiological factors has been recorded. Data from Central Europe, where in the past healthcare and economy sectors were different, are rare.

Objective. The aim of this study was to discover the changes related to OA during a four decade long period in the Slovak Republic.

Materials and method. The study included patients whom OA was reported during 1980-2016. All cases of OA were divided into four decades. The prevalence of OA, changes in etiological factors and key diagnostic methods were evaluated. All decades were analysed separately and compared to one another.

Results. During 1980-2016, OA was reported in 155 patients. OA was most often found in the second decade (6.4 cases per year), the lowest number of cases was diagnosed in the third decade (2.1 cases per year). Since 1988, an increasing prevalence of OA was observed with the peak in 1992, followed by the significantly progressive decrease during subsequent years. In the fourth decade, a mild increase in OA causes was recorded again. In the first and second decades, agricultural allergens were the dominant agents, which were replaced by chemical factors in the last decade. The most frequently used key diagnostic methods in 1980-2009 were skin tests, during the fourth decade the importance of this method declined. However, specific BPT a serial BPT were more frequently used in the fourth decade.

Conclusion. The number of OA cases induced by agricultural allergens declined, which was connected with a decrease of total OA cases. The current problem is the OA induced by the chemicals, which increased significantly in the last decade, even the possibility of underdiagnosed OA cases still exists.
\end{abstract}

\section{Key words:}

occupational asthma, etiological agents, allergens, chemical factors, bronchial hyperresponsiveness, skin prick tests, specific broncho-provocation test

\section{INTRODUCTION}

Occupational asthma $(\mathrm{OA})$ is the most common occupational lung disease in industrialized countries, which affects the population at the productive age. This has consequences not only for the patient and health insurance system but also for the employer and social insurance system. In the last decades, there has been an increase in knowledge about work exposure and the onset of asthma. Studies estimate that the work environment causes $15-20 \%$ of all asthma cases [1]. In young adults, this number varies between 5-10\% [2], but there are significant regional differences. A longitudinal study from Europe confirmed the $6 \%$ prevalence of OA in northern Europe, $23 \%$ in southern Europe and $12 \%$ in central Europe [3]. A multinational study revealed that $26 \%$ of subjects reported exposure to vapours, gas, dust, fumes in their work [4]. As much as $48 \%$ of males and $40 \%$ females could be exposed to one or more asthmagens in their work [5].

Address for correspondence: Slavomír Perečinský Department of Occupational Medicine and Clinical Toxicology, Medical Faculty, P. J. Safarik University and the L. Pasteur University Hospital, Rastislavova 43, 04190 Košice, Slovak Republic e-mail: slavomir.perecinsky@upjs.sk

Received: 05.03.2018; accepted: 30.03.2018; first published: 11.05 .2018
The list of agents with a potential to induce asthma includes 372 different allergens and 184 irritants [6]. Of these, flour, isocyanates, latex, persulphate salts, aldehydes, animals, wood dust, metals, and/or enzymes are responsible for 50-90 $\%$ of reported cases [7]. However, in some European studies, a decrease of these typical etiological factors has been recorded [7-9]. Generally, in Europe, there is a decreasing trend in the prevalence of OA, with some exceptions in a few countries. This decline corresponds with the introduction of legislative measures on chemical exposure [10]. However, the social and healthcare sectors have demonstrated a growing number of OA cases related to cleaning products $[8,11]$. Conversely, typical risky sector for OA is agriculture. However, in the last decades there is a reduction in exposure to agricultural allergens, and thus, fewer cases of OA are reported. The highest number of studies which followed up trends and changes in OA was performed in western or northern Europe. Many of them are usually processing the period of about 1020 years $[7-9,12]$, only a few studies are focused on a longer period [13]. However, data from Central Europe, including the Slovak Republic are rare. The Slovak Republic belongs to the post-Communist countries in which some significant events took place in the lasts decades. A disintegration of 
the east European socialist block at the end of 1989 resulted in dramatic changes in the economic sector. In 2004, the Slovak Republic joined the European Union. All these facts demonstrate the specific situation in Slovakia, which is not comparable to western European countries.

\section{OBJECTIVE}

The aim of this study was to discover whether the changes related to OA have a similar character compared to the Western European countries, and to follow up the trends in the prevalence of $\mathrm{OA}$, changes in etiological factors, and the diagnostic methods used in clinical practice during a period of almost forty years.

\section{MATERIALS AND METHOD}

The study included the patients with OA who were in the database of the Department of Occupational Medicine and Clinical Toxicology at the Louis Pasteur University Hospital in Košice, Slovakia. The database comprises patients who had been diagnosed with OA and reported by this department during the period 1980-2016. At present, the standard procedure for the confirmation of asthma is initiated by the admission of the patient who suffers from respiratory problems at work to the ambulance or department of occupational medicine. In the Slovak Republic, the centre for occupational respiratory diseases is the Department of Occupational Medicine and Clinical Toxicology of Louis Pasteur University Hospital in Košice. On admission, all patients undergo a basic examination by a specialist, followed by lung function tests. An immunoallergological examination is then performed. This consists of confirmation of sensitization to a suspected allergen of the occupational environment, if available. Simultaneously, the sensitization to common inhalant airborne allergens is tested, and skin prick tests or serum specific IgE antibodies test are performed. Positivity of skin tests (prick test or epicutaneous tests) or blood tests with the history of typical respiratory symptoms at the workplace makes the diagnosis of occupational asthma very probable. After the assessment of work conditions by the hygienic worker, it should be decided whether bronchial asthma is considered an occupational. Another diagnostic method is the elimination/resume test. The results of elimination/resume test are considered positive if the clinical symptoms are absent while the patient is out of the workplace, and the worsening of the clinical state is observed after repeated exposition.

A specific provocation test is performed by inhalation of the suspected allergy-inducing agent from the workplace. The last diagnostic method is serial bronchoprovocation test (BPT), consisting of repeated methacholine bronchoprovocation tests. The first is performed while the patient is exposed to asthma-inducing agents in the workplace. Then the second methacholine bronchoprovocation test is performed, after the patient is excluded from the workplace, usually during his work disability. The severity of bronchial hyperresponsiveness after each test is compared. The serial bronchoprovocation test is positive if the bronchial hyperresponsiveness is milder or absent during the work incapacity, compared to the results of the first test. Positivity of the skin test (or specific IgE antibodies), elimination/resume test, specific bronchoprovocation test or serial bronchoprovocation test confirms OA. In some cases, if any objective method could not be performed, OA could be reported without notification by objective diagnostic methods. In this case, diagnosis is confirmed on the basis of the patient's symptoms associated with work environment and documented by a pulmonologist. Also, the presence of negative skin test or specific IgE to common allergens is needed.

All cases of OA evaluated in this study were divided into four decades. The first decade consists of patients who were diagnosed with OA during the years 1980-1989. The second decade includes a period of 1990-1999, the third decade included the years from 2000-2009, and the fourth decade included the years 2010-2016.

In the presented study, the prevalence of occupational asthma for the period of 1980-2016, changes in etiological factors causing OA and changes in key diagnostic methods were evaluated. Additionally, changes in gender, average age of the patients diagnosed with $\mathrm{OA}$, and an average exposition to the harmful agents were followed- up. All decades were evaluated separately and compared to one another.

Etiological factors were divided into five groups agricultural allergens (animal dander, hay, straw, pollen, different types of agricultural dust, moulds), food industry allergens (flour, pastry additives), textile allergens (wool, cotton, synthetic material, leather), chemicals (usually low molecular allergens or irritant agents) and other etiological factors (mites, tobacco dust and wood). As mentioned above, the changes in key diagnostic methods during the decades were also evaluated. A key diagnostic method was the the one which definitely confirmed OA-positivity of skin tests or specific IgE antibodies, elimination/resume test, specific provocation test, and serial bronchoprovocation test. Each method has been explained in more detail above.

Statistical analysis was performed using the software DELL - STATISTICA version 13.0. To compare the changes in diagnostic methods between individual decades, $\chi 2$ test was used. Exposure time between several types of etiological factors was compared by Mann-Whitney test.

\section{RESULTS}

During 1980-2016 OA was reported in 155 patients. In general, OA was most often reported in the second decade (average 6.4 cases per year). In contrast, the lowest number of cases was diagnosed in the third decade $(2.1$ cases per year). There were no significant changes in the number of OA cases in the first decade. Since 1988, an increasing incidence of OA was observed with the peak in 1992, followed by the significantly progressive decrease in the rest of the second decade. During the third decade, there was a stable trend with a few cases of OA. In the last decade, a mild increase of OA incidence was recorded again (Fig. 1).

Some differences have been noticed between the affected genders. OA was more frequent in men only in the third decade, on the contrary, in the first, second, and fourth decade women with $\mathrm{OA}$ prevailed. It was significant, especially in the second decade.

The average age of patients with diagnosed OA was almost the same in all decades. However, the time of exposition to harmful agents decreased progressively (Tab. 1). 


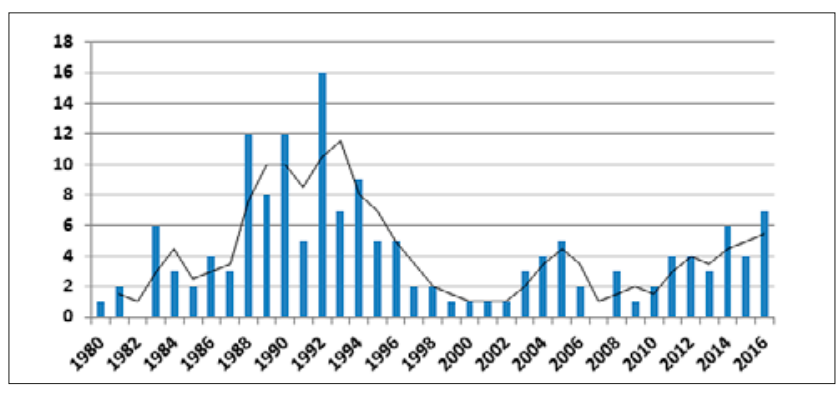

Figure 1. Number of new cases reported annually during 1980-2016

Table 1. Basic characteristics of participants divided into decades

\begin{tabular}{lcccc}
\hline Decade & First & Second & Third & Fourth \\
\hline Number of cases & 41 & 63 & 21 & 30 \\
\hline Cases per year & 4.1 & 6.3 & 2.1 & 4.29 \\
\hline Men/women (\%) & $44 / 56$ & $21 / 79$ & $52 / 48$ & $40 / 60$ \\
\hline Average age & $44( \pm 10)$ & $44( \pm 9)$ & $45( \pm 11)$ & $47( \pm 10)$ \\
\hline $\begin{array}{l}\text { Average exposition } \\
\text { time (months) }\end{array}$ & $214( \pm 108)$ & $210( \pm 112)$ & $159( \pm 136)$ & $182( \pm 121)$
\end{tabular}

Significant changes in etiological factors have been recorded. While in the first and second decade agricultural allergens were the most frequent agents causing OA, during the next two decades their significance dropped considerably. However, a marked increase in the impact of chemical factors, especially cleaning products and disinfectants, was observed in the last decade. In the first and second decade, these factors were of a minor importance. Food industry allergens as etiological factors of OA have shown a stable trend. Only in the third decade, the relative increase was seen (Tab. 2). The list of chemical factors inducing OA is in Table 3.

Table 2. Number of etiological factors inducing OA during the 4 evaluated decades (in 3 patients etiological factor was unknown)

\begin{tabular}{lcccc}
\hline Decade & First & Second & Third & Fourth \\
\hline Food & $12(31.6 \%)$ & $13(20.6 \%)$ & $10(47.6 \%)$ & $6(20.0 \%)$ \\
\hline Agriculture & $17(44.7 \%)$ & $36(57.1 \%)$ & $2(9.5 \%)$ & $3(10.0 \%)$ \\
\hline Textile & $4(10.5 \%)$ & $8(12.7 \%)$ & $1(4.8 \%)$ & $0(0.0 \%)$ \\
\hline Chemicals & $4(10.5 \%)$ & $6(9.5 \%)$ & $7(33.3 \%)$ & $19(63.5 \%)$ \\
\hline Other & $1(2.6 \%)$ & $0(0.0 \%)$ & $1(4.8 \%)$ & $2(6.7 \%)$ \\
\hline
\end{tabular}

Overall, higher prevalence of OA was noticed in women exposed to agricultural allergens, textile allergens, and chemical factors. However, differences were present between the decades. Only food industry related allergies were more frequent in men during all evaluated decades, except the second decade (Tab. 4).

The longest exposure time was recorded in OA cases induced by the agricultural allergens ( $233 \pm 110$ months), followed by the textile allergens ( $200 \pm 114$ months) and food industry allergens (184 \pm 133 months). On the other hand, the chemical allergens exhibited the shortest exposure time (182 \pm 114 months). There was found a statistically significant difference (Mann-Whitney test) in the exposure time between the agricultural allergens and chemicals $(\mathrm{p}<0.05)$ and border significance between the agricultural allergens and food industry allergens $(\mathrm{p}=0.053)$.
Table 3. List of chemical agents inducing OA in each decade

\begin{tabular}{lcccc}
\hline Decade & First & Second & Third & Fourth \\
\hline Hairdressing chemicals & 2 & - & - & - \\
\hline Formaldehyde & - & 1 & - & - \\
\hline Acids & 1 & - & - & - \\
\hline Isocyanates $^{\prime}$ & - & 1 & - & 2 \\
\hline Metals ${ }^{\text {a }}$ & - & 1 & 1 & 1 \\
\hline Organic solvents $^{\text {Cleaning products and Disinfectants }}{ }^{\text {b }}$ & - & 1 & - & 2 \\
\hline Glutaraldehyde & - & 1 & 2 & 9 \\
\hline Nitric gases & - & - & 2 & - \\
\hline Mineral oils & - & - & 1 & - \\
\hline Calcium carbonate & - & - & 1 & - \\
\hline Aromatic carbohydrates & - & - & - & 3 \\
\hline Cyanoacrylate & - & - & - & 1 \\
\hline Welding fumes & - & - & - & 1 \\
\hline Nonspecific & 1 & - & - & - \\
\hline
\end{tabular}

${ }^{a}$ cobalt, aluminium; ${ }^{b}$ chlorine-releasing, chloramine, potassium hydroxide

Table 4. Number of etiological factors inducing OA in man (m) vs. woman (w) in each decade (in 3 patients etiological factor was unknown)

\begin{tabular}{lcccccccccc}
\hline & \multicolumn{2}{c}{ First } & \multicolumn{2}{c}{ Second } & \multicolumn{2}{c}{ Third } & \multicolumn{2}{c}{ Fourth } & \multicolumn{2}{c}{ Total } \\
\hline Factor & $\mathrm{m}$ & $\mathrm{w}$ & $\mathrm{m}$ & $\mathrm{w}$ & $\mathrm{m}$ & $\mathrm{w}$ & $\mathrm{m}$ & $\mathrm{w}$ & $\mathrm{m}$ & $\mathrm{w}$ \\
\hline Food & 10 & 2 & 4 & 9 & 7 & 3 & 4 & 2 & 25 & 16 \\
\hline Agriculture & 2 & 15 & 6 & 30 & 2 & 0 & 2 & 1 & 12 & 46 \\
\hline Textile & 2 & 2 & 1 & 7 & 0 & 1 & 0 & 0 & 3 & 10 \\
\hline Chemicals & 1 & 3 & 2 & 4 & 2 & 5 & 7 & 12 & 12 & 24 \\
\hline Other & 1 & 0 & 0 & 0 & 0 & 1 & 1 & 1 & 2 & 2 \\
\hline Total & 16 & 22 & 13 & 50 & 11 & 10 & 14 & 16 & 54 & 98 \\
\hline
\end{tabular}

Moreover, there were recorded differences in the key diagnostic methods used for confirmation of the OA. While the skin tests (or specific IgE antibodies) were the most frequently used method in 1980-2009, during the fourth decade the importance of this method declined ( $\chi^{2}$ test; $\mathrm{p}<0,001)$. Similarly, the importance of elimination/resume test decreased progressively. Conversely, during the fourth evaluated decade, the OA was more frequently reported without the use of a specific objective method compared with the past three decades. However, specific BPT a serial BPT were more frequently used in the fourth decade, whereas these methods were not used in the first and second decade (Tab. 5).

Table 5. Key diagnostic methods (shown in absolute number and in percentage)

\begin{tabular}{lcccc}
\hline Diagnostic method & First & Second & Third & Fourth \\
\hline Skin test/specific IgE & $22(58.0 \%)$ & $40(69.0 \%)$ & $12(63.0 \%)$ & $11(37.0 \%)$ \\
\hline Elimination/resume & $14(37.0 \%)$ & $17(29.0 \%)$ & $2(11.0 \%)$ & $1(3.0 \%)$ \\
\hline Specific BPT & 0 & 0 & $2(11.0 \%)$ & $4(13.0 \%)$ \\
\hline Serial BPT & 0 & 0 & $1(5.0 \%)$ & $2(7.0 \%)$ \\
\hline No specific method & $2(5.0 \%)$ & $1(2.0 \%)$ & $2(11.0 \%)$ & $12(40.0 \%)$ \\
\hline
\end{tabular}




\section{DISCUSSION}

The study demonstrates significant changes in all aspect of OA during the four evaluated decades. The progressive increase in incidence was observed during 1980-1992, followed by a decrease especially at the end of the 1990s, and then a stabilized trend with only a few cases. A mild increase in incidence was recorded in the last years. Etiological factors and key diagnostic methods have also changed during the four decades; changes in OA have also been reported from other countries. Since 2000, more studies have been performed, and extensive studies conducted in the period of 2000-2012 in several western European countries reported a significant decrease in a number of OA cases [10]. Similarly, the complex changes in etiological factors and in economic sectors have been observed within Europe [7-9]. Similar results have been obtained from Canada, where the incidence of OA and workexacerbated asthma was lower during 2008-2015, compared to 2000-2007 [14]. Vandenplas studied OA during the 1990s [7] and Finnish authors during the 1980s [12, 15], but in all cases, the studied period was shorter compared to the current study. During a long-term study performed by van Kampen in the 1970s, the peak of OA incidence was observed in 1990, followed by a constant decrease in the number of reported cases [13]. These findings are comparable with the results of the current study. The changes in prevalence of OA closely correlate with the changes of etiological factors causing the disease.

At the end of the first decade and at the beginning of the second decade, the most important etiological factors inducing OA were agricultural allergens, and the number of cases was relatively high. Allergic diseases belong to the most common diseases in agricultural sector. It has been clearly confirmed that the risk of asthma increases, and lung function impairment grows, with the increasing length of time in farming $[16,17]$. Other studies have confirmed the decline in number of $\mathrm{OA}$ cases as a result of the weakening exposure to agricultural allergens. This fact could also be connected with the improvement in farming conditions [18], but a more probable explanation is the general reduction in the quantity of cattle in Europe. In some countries, this reduction is related to entry into the European Union [15, 19]. In the Slovak Republic the number of cattle dropped by two-thirds in 2008, compared to 1990, and the decrease continues progressively. In 1989, more than 360.000 people were employed in agriculture, but in 2014 only 51.500 people were thus employed [20]. This fact could explain the significant reduction in OA cases during the third and fourth decades. It was discovered that the last case of OA in the agricultural sector was reported in 1997, with no other case reported until 2008 (data not shown).

In general, however, agriculture is connected with one paradox: for instance, Sozańska described that after the reduction in the number of cattle in the Sibilant Region in Poland, there was a significant increase in atopy and allergic respiratory diseases [19]. This demonstrates the protective effect of farming [21]; consequently, young farmers have a low prevalence of asthma. On the other hand, farmers who are exposed to high levels of occupational dust containing more agents (allergens, bacteria, moulds, irritants) for many years are at risk for the onset of asthma, often even non-IgE mediated, at older age [22]. The presented study confirms this theory. Patients with OA induced by agricultural allergens and exposed to these agents for a longer time, compared to patients in whom there were other etiological factors, especially chemicals and/or food industry allergens, have been confirmed as being responsible for OA. Similarly, Broding noted a significantly longer exposure in sick farmers compared to bakers with confirmed OA [23]. Whereas in the current study, a dramatic decline in the number of OA was observed at the end of the second and during the third decades, especially due to the reduction of farming. A decrease in other etiological factors has also been reported in some other countries.

OA caused by food industry allergens has shown a relatively stable trend with the highest prevalence in the third decade in which there were recorded a few cases of OA caused by another economic sector, except for food industry. Baker's asthma belongs to the most common forms of OA; therefore, there is relatively more knowledge about it also among non-occupational medical doctors. Several types of flour and additives could induce OA in the food industry with flour commonly described as the most frequent/common etiological factor responsible for OA [24-27]. However, in the last few years, fewer cases of flour-induced OA have been recorded, compared to the situation in the past $[7,9]$.

In the presented study, the last decade was characterized by a mild increase in OA, with OA induced by chemicals occurring the most frequently. The number of OA cases related to work in other sectors was quite low. More cases of OA, mostly among nurses and cleaners, were recoginised due to the impact of cleaning and disinfection products, compared with the other decades. Observation of a significant increase in the influence of these factors on the onset of asthma is an important finding in the current study, and the results correspond with other recent studies. Paris showed that fewer cases of OA are induced by isocyanates, latex and aldehydes; however, an increase was observed for cases related to exposure to quaternary ammonium compounds in the health care and social sectors [8]. Similarly, in a study from the West Midlands in England there was confirmed a lower incidence of the most common causative agents, except for cleaning products [9]. Another study performed in health care workers from the same region, demonstrated a reduction in latex- and glutaraldehyde-induced asthma. However, a significant increase in OA caused by cleaning products was found [11]. Similarly, a recent study from Poland reported that work-related asthma was very common in professional cleaners. OA was present in $16 \%$ and workexacerbated asthma in $30 \%$ of them. Latex and disinfectants played important roles [28]. The importance of isocyanates as leading factors of $\mathrm{OA}$ in many industrialized countries has decreased in recent years [7, 8, 29]. Gotzev showed a decrease in cases of OA and work exacerbating asthma resulting from isocyanates, especially during the period of 2008-2015 [14]. However, during 2000-2007, the number of isocyanateinduced OA cases was very similar to a previous study from the same clinic in 1978-1987 [30]. This decrease was probably caused by the introduction of effective surveillance programmes. Nevertheless, these results are not applicable to the presented study and could not explain the decline of $\mathrm{OA}$, because isocyanate- induced OA was found only in three patients during all four decades.

Because of the changes in etiological agents, the value of common allergological diagnostic methods (skin tests and specific IgE examination) is much lower at present, especially 
during recent decades, compared to the past. Unfortunately, due to this fact, in the last decade OA was very often diagnosed without using an objective method. The medical findings from the patient's pulmonologist have to be awaited, and who should record the asthmatic symptoms in connection with work. In this case, the OA may be misdiagnosed and many cases may be lost. Also, the risk of false positive diagnosis exists, but probably in the conditions, this possibility is much less frequent. The peak expiratory flow rate monitoring, another classic diagnostic method, is not performed in the authors' Department of Occupational Medicine and Clinical Toxicology. At first, it happens very often that patients are not able to return to the hazardous workplace. Secondly, many patients have a tendency towards simulation or noncompliance. Therefore, the specific inhalation challenge (SIC) should be performed more frequently. It is considered to be a gold diagnostic standard. SIC has the higher sensitivity and specificity compared to the skin-prick tests, airway hyper-responsiveness single or serial test and peak expiratory flow rate monitoring [31]. This should distinguish OA from the work exacerbate asthma, especially if the assessment of sensitization is not specific enough [32]. Although in the fourth decade a relatively high proportion of OA cases were diagnosed only on the basis of pulmonologists' findings, specific methods are performed more often than in the past. Therefore, we can assume that in the future, reporting of OA without the use of objective diagnostic methods will be minimalized.

Overall, in many countries, OA remains underreported. Despite an increasing number of respiratory allergies in the general population, OA has shown a decline. Korean authors have demonstrated a very low incidence rate of $\mathrm{OA}$ until the late 1990s, with an increasing trend in the 2000s, and later another decrease [33]. In Poland, which borders with Slovakia, betweeen 1998-2011, a significant decline was observed. This could have been caused by the lack of strategies for identification of potential allergenic factors, and the lack of standardized diagnostic methods and surveillance systems [27].

A very important fact is to consider the potential occupational etiology of asthma, and subsequently, to send the patient to a specialized department. The practical doctors and other specialists, especially allergologists and pulmonologists, play a key role in proper diagnosis. However, the results of an Italian study have confirmed that allergologists do not seem to be focused on OA in daily clinical practice [25]. Similar findings were noticed in pulmonologists, where important barriers to consider in a diagnosis of OA were, e.g. physicians' low awareness, lack of knowledge and time. Moreover, a very important fact was the patients' concerns regarding job security and fear of losing work and income. Pulmonologists most readily diagnose $\mathrm{OA}$ when it occurs in response to an agent or workplace situation with which they are familiar [34]. Another barrier is the delay in diagnosing of OA; for example, in Ontario, Canada, the mean time to diagnose the OA was 4.7 years. The main reasons for this delay were the lack of knowledge about patient's workplace by the primary care physician, fear of losing job or change of job. [35]. Sometimes, this delay causes asthma to be confirmed only after the exposure stops. In which case, the diagnostic methods, like the serial peak expiratory flow rate in the patient's workplace, elimination/resume test or serial broncho-provocation test, should not be performed.
The whole period is characterized by the small number of cases which is a major limitation of the study. But trends and changes are clearly recognized because, for these, the studied period is long enough. It captures all important political and economic changes in many sectors which also had a significant impact on the healthcare system. One of the problems in the Slovak Republic is the absence of a central register of occupational diseases, which deals with OA in more detail, similar to the Finnish Registry of Occupational Diseases (FROD). Most probably, it would also be very helpful for comparison of the situation in other countries.

\section{CONCLUSIONS}

The number of OA cases induced by agricultural allergens declined during the second decade. This was connected with a decrease of total OA cases in this period as a result of a reduction in agriculture, while in the food and textile industries the number of cases was relatively stable or showed a decline. The current problem is the OA induced by cleaning products and chemicals, the occurrence of which increased significantly in the last decade. However, the possibility of underdiagnosed OA cases exists. Some cases may be overlooked due to inappropriate knowledge about the exposure to new or less frequent agents and/or the lack of specific diagnostic methods. Therefore, a close collaboration between the occupational physician with other primary and secondary physicians, as well as the need for performing specific provocation tests, is necessary. The early and accurate diagnosis of OA is crucial because of the impact on the patient's health, as well as the social and financial consequences.

\section{REFERENCES}

1. Torén K, Blanc PD. Asthma caused by occupational exposures is common - a systematic analysis of estimates of the populationattributable fraction. BMC Pulm Med. 2009; 9: 7.

2. Kogevinas M, Antó JM, Sunyer J, Tobias A, Kromhout H, Burney P. Occupational asthma in Europe and other industrialised areas: a population-based study. European Community Respiratory Health Survey Study Group. Lancet. 1999; 353: 1750-1754.

3. Kogevinas M, Zock JP, Jarvis D, Kromhout H, Lillienberg L, Plana E et al. Exposure to substances in the workplace and new-onset asthma: an international prospective population-based study (ECRHS-II). Lancet. 2007; 370(9584): 336-341.

4. de Vocht F, Zock JP, Kromhout H, Sunyer J, Antó JM, Burney P et al. Comparison of self-reported occupational exposure with a job exposure matrix in an international community-based study on asthma. Am J Ind Med. 2005; 47(5): 434-442.

5. Fritschi L, Crewe J, Darcey E, Reid A, Glass DC, Benke GP et al. The estimated prevalence of exposure to asthmagens in the Australian workforce, 2014. BMC Pulm Med. 2016; 9(4):16-48.

6. Baur X, Bakehe P, Vellguth H. Bronchial asthma and COPD due to irritants in the workplace - an evidence-based approach. J Occup Med Toxicol. 2012; 7(1): 19.

7. Vandenplas O. Occupational asthma: etiologies and risk factors. Allergy Asthma Immunol Res. 2011; 3(3): 157-167.

8. Paris C, Ngatchou-Wandji J, Luc A, McNamee R, Bensefa-Colas L, Larabi L et al. Work-related asthma in France: recent trends for the period 2001-2009. Occup Environ Med. 2012; 69(6): 391-397.

9. Walters GI, Kirkham A, McGrath EE, Moore VC, Robertson AS, Burge PS. Twenty years of SHIELD: decreasing incidence of occupational asthma in the West Midlands, UK? Occup Environ Med. 2015; 72(4): 304-310.

10. Stocks SJ, McNamee R, van der Molen HF, Paris C, Urban P, Campo G et al. Trends in incidence of occupational asthma, contact dermatitis, noise-induced hearing loss, carpal tunnel syndrome and upper limb 
musculoskeletal disorders in European countries from 2000 to 2012. Occup Environ Med. 2015; 72(4): 294-303.

11. Walters GI, Moore VC, McGrath EE, Burge PS, Henneberger PK. Agents and trends in health care workers'occupational asthma. Occup Med (Lond). 2013; 63(7): 513-516.

12. Karjalainen A, Kurppa K, Virtanen S, Keskinen H, Nordman H. Incidence of occupational asthma by occupation and industry in Finland. Am J Ind Med. 2000; 37(5): 451-8.

13. van Kampen V, Merget R, Butz M, Taeger D, Brüning T. Trends in suspected and recognized occupational respiratory diseases in Germany between 1970 and 2005. Am J Ind Med. 2008; 51(7): 492-502.

14. Gotzev S, Lipszyc JC, Connor D, Tarlo SM. Trends in Occupations and Work Sectors Among Patients With Work-Related Asthma at a Canadian Tertiary Care Clinic. Chest. 2016; 150(4): 811-818.

15. Piipari R, Keskinen H. Agents causing occupational asthma in Finland in 1986-2002: cow epithelium bypassed by moulds from moisturedamaged buildings. Clin Exp Allergy. 2005; 35(12): 1632-1637.

16. Pahwa P, Senthilselvan A, McDuffie HH, Dosman JA. Longitudinal decline in lung function measurements among Saskatchewan grain workers. Can Respir J. 2003; 10(3): 135-141.

17. Post W, Heederik D, Houba R. Decline in lung function related to exposure and selection processes among workers in the grain processing and animal feed industry. Occup Environ Med. 1998; 55(5): 349-355.

18. Sigurdarson ST, Gudmundsson G, Sigurvisdottir L, Kline JN, Tomasson K. Respiratory disorders are not more common in farmers. Result from a study on Icelandic animal farmers. Resp Med. 2008; 102: 1839-1843.

19. Sozanska B, Błaszczyk M, Pearce N, Cullinan P. Atopy and allergic respiratory disease in rural Poland before and after accession to the European Union. J Allergy Clin Immunol. 2014; 133(5): 1347-1353.

20. Jamborová M, Masár I. Development trends of employment in the agricultural sector and food production within last decade (2005-2014) in Slovakia. Ekonomika polnohospodárstva. 2015; 15 (4): 109-123. (article in Slovak).

21. von Mutius E. 99th Dahlem conference on infection, inflammation and chronic inflammatory disorders: farm lifestyles and the hygiene hypothesis. Clin Exp Immunol. 2010;160:130-5.

22. Rask-Andersen A. Asthma increase among farmers: a 12-year followup. Ups J Med Sci. 2011; 116(1): 60-71.
23. Broding HC, Frank P, Hoffmeyer F, Bünger J. Course of occupational asthma depending on the duration of workplace exposure to allergens a retrospective cohort study in bakers and farmers. Ann Agric Environ Med. 2011; 18(1): 35-40.

24. Ameille J, Hamelin K, Andujar P, Bensefa-Colas L, Bonneterre V, Dupas D et al. Occupational asthma and occupational rhinitis: the united airways disease model revisited. Occup Environ Med. 2013; 70(7): 471-475.

25. Moscato G, Maestrelli P, Bonifazi F, Troise C, Caminati M, Crivellaro $\mathrm{M}$ et al. OCCUPATION study (OCCUPationl asthma: a naTIONal based study): a survey on occupational asthma awareness among Italian allergists. Eur Ann Allergy Clin Immunol. 2014; 46(1): 26-29.

26. Endre L. Occupational asthma in Hungary. Orv Hetil. 2015; 156(19): 769-778. (article in Hungarian).

27. Szeszenia-Dąbrowska N, Wilczyńska U. Occupational diseases in Poland--an overview of current trends. Int J Occup Med Environ Health. 2013; 26(3): 457-470.

28. Lipinska-Ojrzanowska AA, Wiszniewska M, Walusiak-Skorupa JM. Work-related asthma among professional cleaning women. Arch Environ Occup Health. 2017; 72(1): 53-60.

29. Buyantseva LV, Liss GM, Ribeiro M, Manno M, Luce CE, Tarlo SM. Reduction in diisocyanate and non-diisocyanate sensitizer-induced occupational asthma in Ontario. J Occup Environ Med. 2011; 53(4): 420-426

30. Tarlo SM, Broder I. Outcome of assessments for occupational asthma. Chest. 1991; 100(2): 329-335.

31. Lemière C. When to suspect occupational asthma. Can Respir J. 2013; 20(6): 442-444

32. Wiszniewska M, Walusiak-Skorupa J. Diagnosis and frequency of workexacerbated asthma among bakers. Ann Allergy Asthma Immunol. 2013; 111(5): 370-375.

33. Oh SS, Kim KS. Occupational asthma in Korea. J Korean Med Sci. 2010; $25: 20-25$.

34. Parhar A, Lemiere C, Beach JR. Barriers to the recognition and reporting of occupational asthma by Canadian pulmonologists. Can Respir J. 2011; 18(2): 90-96.

35. Poonai N, van Diepen S, Bharatha A, Manduch M, Deklaj T, Tarlo SM. Barriers to diagnosis of occupational asthma in Ontario. Can J Public Health. 2005; 96(3): 230-233. 